\title{
O processo criativo e a tessitura de projetos acadêmicos de pesquisa
}
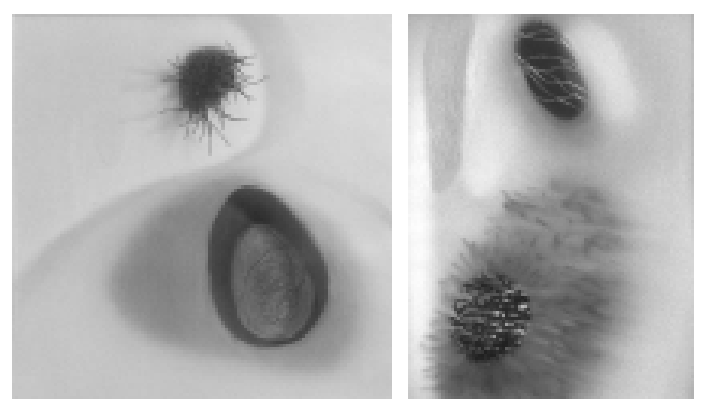

\author{
Carlos Antonio Alves Pontes ${ }^{1}$ \\ Abel Menezes Filho' \\ André Monteiro Costa ${ }^{3}$
}

A vida não se faz de vez
$A$ Vanda Aquino,
que nos inspirou e reuniu.

Os estudantes de pós-graduação se deparam com dificuldades e tensões, ao terem que se envolver com a construção de trabalho monográfico, requisito necessário para a obtenção do grau de doutor, mestre ou especialista. É imprescindível a elaboração de um projeto obviamente adequado para cada grau de titulação, o que resulta em níveis de dificuldades e de tensões crescentes. Embora existam muitos obstáculos a superar no curso das disciplinas teóricas, podemos afirmar que no processo de elaboração dos projetos e, posteriormente, nas monografias, dissertações de mestrado e teses de doutorado os desafios são ainda maiores. A situação de ter de apresentar um projeto de pesquisa, um documento escrito de sua própria autoria e submetê-lo à apreciação de uma banca de examinadores pode mexer com o estado emocional do estudante, a ponto de, muitas vezes, não conseguir elaborar um texto com a qualidade que seria esperada e correspondente ao nível de aprendizagem alcançado com a conclusão das disciplinas ou, até mesmo, não lograr cumprir os prazos de entrega. Em suporte a tal situação, é possível encontrar uma farta literatura técnico-científica sob diversos títulos: metodologia científica, elaboração de projetos de pesquisa, como fazer uma tese etc., que vão compor os inúmeros manuais disponíveis em qualquer livraria especializada. Esses tratam de propor estruturações de projetos, evidentemente fundamentadas, tanto epistemológica quanto metodologicamente. Alguns manuais desenvolvem, inclusive, uma discussão sobre o processo de elaboração de um projeto, tanto no que diz respeito aos conteúdos quanto à dinâmica para desenvolvê-los. No entanto, há uma lacuna no que diz respeito ao próprio processo do escrever, da produção do texto em si.

\footnotetext{
${ }^{1}$ Pesquisador e professor visitante, Departamento de Saúde Coletiva, Centro de Pesquisas Aggeu Magalhães, Fundação Oswaldo Cruz, Recife, PE. <cpontes@cpqam.fiocruz.br>

${ }_{2}^{2}$ Pesquisador e professor, Departamento de Saúde Coletiva, Centro de Pesquisas Aggeu Magalhães, Fundação Oswaldo Cruz; Núcleo de Saúde Pública e Desenvolvimento Social, Universidade Federal de Pernambuco (UFPE), Recife, PE. <abelm@cpqam.fiocruz.br>

${ }^{3}$ Pesquisador e professor, Departamento de Saúde Coletiva, Centro de Pesquisas Aggeu Magalhães, Fundação Oswaldo Cruz, Recife, PE. <andremc@cpqam.fiocruz.br>
}

${ }^{1}$ Av. Moraes Rego, s/n

Campus da UFPE - Cidade Universitária

Recife, PE

50.670-420 
O encontro com o papel em branco (a tela em branco na era digital), de um modo geral, é um momento de desafio que, para a maioria das pessoas (principalmente para os iniciantes), pode constituir tensão, angústia e imobilidade. A metáfora mais comum é "vamos ver como o pensamento fica no papel". A aposta é que "num momento de inspiração vou sentar no computador e escrever o texto completo". A expectativa é a de que o texto, de uma só vez, vai sair pronto e acabado. Só então, poderá ser submetido à apreciação de terceiros. As conseqüências, muitas vezes, são, quando não ocorre o descumprimento do prazo, o texto ser de baixa qualidade e o sentimento ser de frustração. Com o objetivo de contribuir para a superação de tais dificuldades, o presente artigo pretende propor uma metáfora vital, com movimentos sucessivos e diferenciações simultâneas aplicáveis ao processo de escrever, de modo a torná-lo mais prazeroso e produtivo e com menores níveis de desgaste emocional.

Inicialmente, são apresentados os fundamentos teóricos no campo da produção do conhecimento e do processo de aprendizagem, tendo como referência uma concepção construtivista para a introdução de uma analogia que vai identificar o texto como um organismo. Em seguida, é assumida uma estrutura de referência de um "projeto-padrão" da literatura disponível, a partir da qual discorremos como se pode processar a elaboração de um projeto. Aplica-se a essa estrutura de referência um processo não-linear de produção em que o texto deve ser escrito como um todo orgânico que, a partir de núcleos indiferenciados, vai desenvolvendo-se, seguindo um processo similar ao desenvolvimento embrionário. $E$, por fim, discorremos sobre as posturas que julgamos adequadas à tessitura propriamente dita.

\section{Ser, emocionar, conhecer}

Desde Immanuel Kant (1724-1804), sabe-se que a realidade em si é inatingível pelo entendimento humano, pelo menos no que se refere à Razão, entendida aqui como sendo a instância intelectual humana. Dessa forma, só teríamos acesso aos fenômenos (como aparecem à nossa experiência), e não aos números (a coisa em si). Para a produção do conhecimento, segundo Kant, seria necessária a existência, a priori, de intuições espaçotemporais capazes de organizar as percepções produzidas pelos sentidos e também de categorias, a priori, do entendimento, que é a "faculdade de pensar o objeto da intuição sensível". Não se deve separá-las, mas distingui-las. O conhecimento surge da reunião de ambas, pois "sem sensibilidade nenhum objeto nos seria dado, e sem entendimento nenhum seria pensado" (Kant, 1996, p.92). Assim, Kant dá início a uma forma de conceber a produção do conhecimento por uma via que não se baseia, apenas, na experiência nem, exclusivamente, na capacidade inata do sujeito epistêmico. Essa via ficou conhecida como sendo uma concepção construtivista do conhecimento. A partir de Kant, outras contribuições foram acrescentadas, notadamente as de Jean Piaget (1896-1980) na primeira metade do século XX e as de Humberto Maturana \& Francisco Varela no final desse mesmo século. Piaget demonstra que as estruturas cognitivas vão desenvolvendo-se em uma interação complexa, do organismo com seu ambiente (Piaget, 2000). Maturana \& Varela (2001) sustentam que a cognição é inerente ao ser vivo, introduzindo o conceito de autopoiese (o que se cria a si mesmo).

A cognição, para Maturana \& Varela (2001), é entendida como um ato de um dado organismo manter a coerência do seu acoplamento estrutural com o seu ambiente. Quando o organismo não é mais capaz de manter essa coerência, fazendo as alterações estruturais próprias, ele perece. Os seres humanos acrescentamos uma dimensão simbólica, ampliando o escopo da cognição ao desenvolver a linguagem. Segundo Maturana (2001), a linguagem surgiu na convivência entre indivíduos que viveram há cerca de três milhões de anos, organizados em pequenos bandos. Assim, nós, seres humanos, nos construímos 
como seres de linguagem, entrelaçando-a ao fluir das emoções. Emoção, para os citados autores, é a disposição corporal, para agir, que especifica um domínio de ação.

Dependendo da emoção que vivenciamos num dado momento, só podemos agir dentro do campo que a emoção permite. Mas a emoção, depois de elaborada, também amplia o campo e nos eleva a outros patamares de autoconsciência. A emoção surge antes da linguagem. Os animais são capazes de experimentá-la. O entrelaçamento do "linguagear" com o "emocionar" vai constituir o conversar. São as conversações que vão constituir as culturas, na medida em que se conservam e são transformadas gerações após gerações (Maturana \& Verden-Zöller, 2004). Dessa forma, a dimensão simbólica se edifica e encontra sustentação a partir do conversar. Antes de sermos racionais, somos seres emocionais. É no fluir das conversações que somos gerados tanto como indivíduos quanto como coletivos. Um ser da nossa espécie que não conviveu entre humanos, no fluir das conversações de uma dada cultura, não se torna humano. O exemplo de seres de nossa espécie criados por outros animais é notório e dramático: quando houve tentativas de socialização humana, esses seres não se adaptaram e logo morreram. As conseqüências de tal concepção - que envolve o conhecer como algo inerente ao ser vivo - e as relações da linguagem, com as emoções e a noção de que o humano só existe por causa de outro humano, são: viver é aprender; as conversações constituem o ser; a aprendizagem é um processo contínuo; e, ainda, tudo tem que ser aprendido, inclusive, a ser "ser humano".

Para Piaget (2000), a aprendizagem é um processo de desequilibração e reequilibração de estruturas cognitivas. Todo conhecimento está ligado a uma ação. À medida que se entra em contato com algo novo a ser aprendido, as estruturas cognitivas anteriores são postas em desacordo. Para haver aprendizagem, é necessário que haja uma re-estruturação interna, com a conseqüente assimilação daquilo a ser aprendido. O processo de aprendizagem vai consistir em transformar, continuamente, os elementos internos construídos pelo sujeito em sua experiência de vida. Piaget sintetiza que a inteligência organiza o mundo, organizando-se a si mesma (Piaget, 2000). Do mesmo modo, a construção de um objeto de estudo, que é um processo de construção do conhecimento, não se dá de forma imediata, mas por aproximações sucessivas, de desequilíbrios e re-equilíbrios, de nexos emocionais e racionais. O próprio ato de escrever um projeto de pesquisa deve ser visto como uma oportunidade de operar essas aproximações.

Embora se tenha a idéia, de forma clara, de qual deve ser a estrutura de um projeto, ou seja, que conteúdos cada parte deva conter, o comum é esperar que sua escrita se dê de forma linear: escrevem-se a problematização e as perguntas; definem-se os objetivos; desenvolve-se a fundamentação teórica; descrevem-se os métodos; traçam-se os contornos operacionais, computando-se os recursos materiais e de tempo; perfilam-se as referências bibliográficas; e, por fim, atende-se às considerações éticas. Mas é forçoso reconhecer que tais partes vão compor um todo organizado; vão constituir um sistema complexo, "um tecer juntos". Isso significa dizer que as partes vão guardar, entre si, relações de interdependência e de interdefinibilidade, características constitutivas desse tipo de sistema (Garcia, 1994). Os objetivos deverão ser redefinidos em função de aspectos operacionais. O problematizar de uma determinada questão pode ser redirecionado com a compreensão que o fundamento teórico venha a revelar na medida em que é elaborado. $\mathrm{O}$ mesmo se pode dizer em relação aos métodos que vão sendo escolhidos em função dos objetivos cujo alcance vai depender dos recursos disponíveis. Assim, devemos reconhecer que a construção de um projeto de pesquisa não é um processo linear; por conseguinte, o ato de escrevê-lo também não o será, pois é reflexo do próprio processo de cognição. É possível, então, admitir que um texto pode ser visto como um organismo e, por analogia, entender que a sua elaboração seria um processo similar ao desenvolvimento embrionário 
de um organismo: uma célula-ovo, indiferenciada, que se divide sucessivamente, fazendo surgir, sincronicamente, novas células, que se vão diferenciando e dando origem a tecidos e órgãos até formarem um organismo maduro.

Devemos também considerar o emocionar no momento de escrever. Sabemos que o momento é de tensão - e não poderia ser de outro modo -, afinal, estamos concentrando atenção para uma determinada tarefa e vamos produzir algo que será submetido à apreciação de terceiros. O olhar do outro nos pode reconhecer como fazendo parte de um grupo, mas a sua desaprovação significaria, para nós, o sentimento de rejeição. Que esperaríamos como resultado de uma escrita se estamos receosos, ansiosos, impacientes, inseguros, desconfortáveis? A palavra "dança", em várias línguas européias - danza, dance, tanz - deriva da raiz tan, que, em sânscrito, significa "tensão" (Garaudy, 1980): os músculos tensos, o corpo todo envolvido, para expressar o indizível com a máxima intensidade. Porém a tensão não precisa ser excessiva, estressante; existe um tônus que nos mantém de pé: é a nossa resistência ante a gravidade. Qualquer ação leva ao aumento dessa tensão básica. A dança - ritmo, emoção, técnica e arte - alterna o tenso com o relaxamento. O processo criativo é tenso, mas não precisa ser de sofrimento; como a dança, pode ser vivido com alegria, confiança, conforto, acolhimento.

\title{
Da estrutura ao processo: a embriogênese é a metáfora
}

Há uma literatura vasta que tem a finalidade, direta ou indiretamente, de auxiliar estudantes de pós-graduação na realização de seus trabalhos monográficos. Existe um campo mais geral acerca da metodologia científica e um outro, sobretudo, a respeito da elaboração de monografias e projetos de pesquisa. Dentre estes, os mais tradicionais e abundantes são os manuais que se referem, em geral, às normas, à estrutura e ao planejamento da pesquisa, como os de França et al. (2003), Costa \& Costa (2001), Parra Filho \& Santos (2001), Rother \& Braga (2001), Rudio (1999), Salomon (1999), Sá et al. (1997), Spector (1997), Gil (1996), Severino (1996), Bastos et al. (1995), Rey (1993) e Lakatos \& Marconi (1992). Outros trabalhos sugerem elementos relevantes aos quais os pesquisadores devem estar atentos nesse processo e que pretendem contribuir para a compreensão de como construir as partes de um projeto, de modo mais consistente, como os de Goldenberg (1999), Beaud (1997), Contandriopoulos et al. (1994) e Eco (1993). Um terceiro grupo de publicações, além daqueles elementos, se propõem a contribuir para a percepção do que ocorre ao pesquisador, na tentativa de resolver as suas dificuldades, e para construção de percursos, como os de Pacheco (1988), Perrota (2004) e o de Tobar \& Yalour (2001). Estes últimos autores vão além no sentido da preocupação com as tensões inerentes ao processo. No livro "Como fazer teses em saúde pública", propõem uma estrutura formada, basicamente, por seis componentes: formulação do problema; marco teórico; metodologia; aspectos operacionais; referências bibliográficas; anexos.

Para os propósitos deste artigo, sugerimos um desdobramento da referida estrutura, para destacar, do componente formulação do problema, a enunciação dos objetivos e criar mais um item, para incorporar os aspectos éticos, como no roteiro a seguir adaptado de Tobar \& Yalour (2001):

\section{Conteúdo dos componentes de um projeto de pesquisa}

\author{
Formulação do problema - A que pergunta quero responder? \\ Objetivos - Geral \\ Específicos: E1, E2, E3
}

Marco teórico - O que sabemos até hoje sobre o problema? Quem estudou?

Há mais de uma posição sobre o problema? Como estudaram? Como vou ler 
einterpretar os dados que obtiver em meu estudo?

Metodologia - Que tipo de pesquisa (desenho) me proponho fazer? Com que dados vou trabalhar? Meus dados serão números ou palavras? Como vou obter os dados? Que quantidade de dados será suficiente para alcançar os resultados a que me proponho? Que vou fazer quando conseguir os dados? Vou processá-los de algum modo? Vou interpretá-los segundo o marco de uma teoria?

Aspectos operacionais - Quais são os resursos humanos, físicos, tecnológicos e econômicos necessários para concretizar meu estudo? Como vou organizar meus recursos no tempo e no espaço? De que forma vou dividir o trabalho? Que fases ou etapas terá minha pesquisa? Que resultados parciais poderá oferecer? Quanto tempo vai levar a pesquisa? Quanto tempo vai levar cada fase?

Aspectos éticos - Quem são os sujeitos da pesquisa? Quais os riscos e os benefícios? Quais as medidas de cuidado e proteção às pessoas que participarão da pesquisa?

Referências bibliográficas

Anexos

O destaque dos objetivos é proposto em razão da possibilidade de serem vistos em seu papel de integradores dos demais componentes; são a especificação de ações para responder às perguntas formuladas e, por sua vez, orientam a metodologia a ser desenvolvida. Portanto, devem manter coerência com a pergunta e a metodologia, além do que vão sofrer restrições pelo menos quanto à sua extensão, ao serem cotejados com os aspectos operacionais, para a realização do projeto. Em outras palavras, o alcance dos resultados desejados deve ser compatível com os recursos disponíveis, particularmente no que se refere ao tempo oferecido a cada nível de formação.

Quanto aos aspectos éticos, sua inclusão se apresenta como essencial em projetos de pesquisa que envolvem seres humanos em particular ou seres vivos de uma forma geral. A inclusão também vai constituir-se em uma oportunidade de refletir e explicitar o sistema de valores que estão em jogo e que vão legitimar uma prática moralmente correta. Embora um projeto de pesquisa possa estar formulado de modo correto, tanto do ponto de vista científico quanto metodológico, pode, no entanto, apresentar implicações éticas nãoaceitáveis, por trazer algum tipo de prejuízo ou constrangimento às pessoas que eventualmente dele participem. A História mostra como é possível cometer crimes hediondos contra a humanidade e desrespeitar os mais elementares direitos da pessoa, do cidadão, em nome da "pesquisa, do progresso e do conhecimento". Portanto, além de serem orientados para o alcance de resultados, científica e academicamente relevante, os projetos devem conter os cuidados necessários para proteger as pessoas, explicitando as responsabilidades dos pesquisadores para com elas, de forma a obter legitimidade social e moral; por tal razão, devem ser submetidos à apreciação de um Comitê de Ética em Pesquisa (CEP) institucionalmente constituído (Schramm, 1999).

Para que fique mais claro o processo criativo, não-linear, e o que estamos dizendo com "a embriogênse é a metáfora"4, descreveremos, sucintamente, o desenvolvimento embrionário e suas correspondências com o texto-projeto (Enciclopédia Mirador, 1986).

${ }^{4} \mathrm{Na}$ construção dessa metáfora agradecemos a contribuição da Professora Idê Gomes Gurgel.
Fecundação: encontro de espermatozóide e óvulo: a primeira semente, o desejo, gera o tema; Ovo ou Zigoto: ativação do novo ser: primeira palavra-chave; 
Blastômeros: a partir do ovo, início da multiplicação celular: multiplicidade, tumulto das palavras, das idéias. Período de busca das fontes, das pessoas, dos meios de comunicação e de informação, das referências bibliográficas, do mapeamento etc; Mórula (células em forma de amora): multiplicação celular em estágio mais avançado: primórdios de uma organização do projeto e do texto. Elaborada a primeira versão;

Blástula: fase de implantação, fixação uterina: projeto e texto mais organizados, nutridos por maior clareza das palavras, idéias e conceitos. Elaborada a segunda versão; Folhetos (ectoderma, endoderma e mesoderma): diferenciação celular em tecidos e órgãos: texto e projeto esboçados - constam todos os seus elementos, mas faltam ajustes e correções.

Elaborada a terceira versão;

Embrião: ser formado, completo: texto e projeto prontos. Versão final.

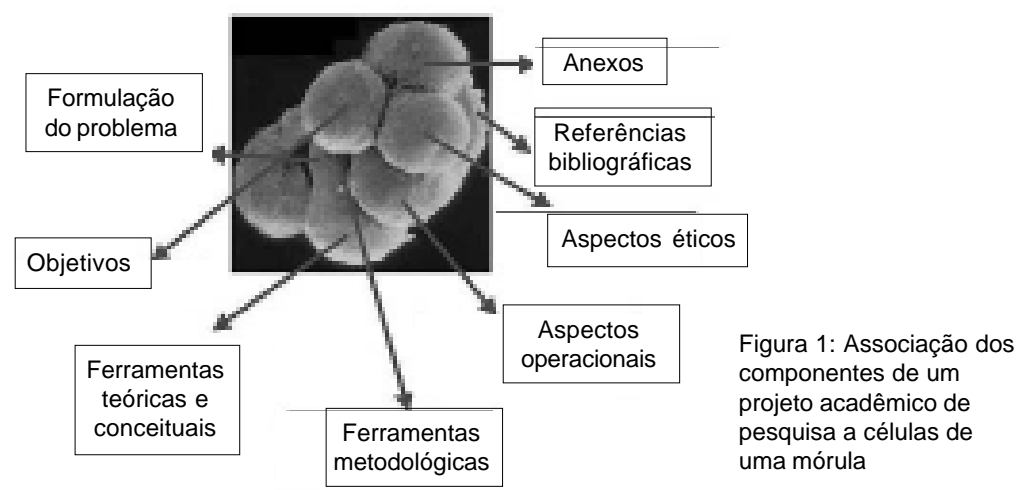

Na figura 1 está representada uma mórula, que é, como vimos, uma seqüência do desenvolvimento de um organismo em algumas espécies. Às suas células está associado cada um dos componentes de um projeto, a partir dos quais será desenvolvido o texto, mantendo-se os nexos causais que comporão, assim, o projeto correspondente. Embora seja possível estabelecer momentos no desenvolvimento de um organismo como um todo, suas partes componentes crescem simultaneamente. Assim, de maneira análoga ao que acontece no desenvolvimento embrionário, é possível proceder a versões sucessivas no processo de construção do projeto e trabalhar, ao mesmo tempo, nos seus vários componentes.

Nossa experiência com alunos do Nesc/CPqAM/Fiocruz nos cursos de especialização em Saúde Coletiva dá uma indicação de que, em três momentos sucessivos, é possível chegar a uma versão completa de um projeto.

Nossa indicação é que a primeira versão seja elaborada a partir da própria experiência do estudante, enriquecida pelo estudo das disciplinas teóricas cursadas e orientada pelos desejos para um determinado tema. Essa é uma dimensão de partida, essencial, pois, como aponta Alves (2000, p.41), "o mundo humano se organiza em torno de desejos". E não há nada mais desgastante do que fazer uma pesquisa sem desejo pelo tema. Assim, propomos que o estudante trabalhe na montagem de um documento que contemple a estrutura do quadro 1 , tentando responder às questões colocadas para cada componente. 
Espera-se que a primeira versão contenha o esboço de um problema na forma de uma pergunta; objetivos gerais e específicos; questões do marco teórico a serem desenvolvidas; e as primeiras propostas de desenvolvimento metodológico. A formulação do problema é essencial, pois, conforme também sugere Alves (2000), o conhecimento só ocorre em situações-problema. Portanto, a pergunta adequada se constitui em algo central na ciência (Tobar \& Yalour, 2001), porque, como vimos, da pergunta iremos construir os objetivos e destes, a metodologia.

Para a segunda versão, o estudante vai trabalhar no sentido de a) desenvolver os textos respectivos a cada componente, procurando apoiar-se na literatura disponível, de modo a contextualizar e reformular, com maior precisão, o seu problema; b) desenvolver um roteiro para orientar a revisão bibliográfica e sistematizar o conhecimento já produzido por outros estudos; c) dar maior amplitude aos procedimentos metodológicos; d) fazer um elenco dos recursos necessários para o desenvolvimento da pesquisa; e) anunciar e hierarquizar as atividades, procurando situá-las no tempo, f) apresentar a versão para crítica do coletivo.

Para a produção da terceira versão é importante o aprofundamento teórico para maior coerência interna, de modo a obter maior precisão e consistência entre as partes do projeto. Embora a Ética, em particular a Bioética, seja ponto de partida e atravesse todo o processo, achamos que este é o momento especialmente adequado para refletir sobre quem são os sujeitos da pesquisa, quais os riscos e benefícios a que estão submetidos, quais as medidas de salvaguardas e cuidados para a proteção das pessoas da pesquisa. Por fim, propomos que a terceira versão, com data de referência estabelecida, também deverá ser apresentada e criticada no coletivo, a exemplo do que foi feito com a segunda versão. Após esse crivo, a versão final poderá ser elaborada.

Os períodos de tempo necessários para elaborar cada versão variam e dependem do tempo total disponível; além do mais, devemos considerar os tempos individuais, que, em geral, são diferentes. E ainda: devem ser respeitados os tempos institucionais dos programas de pós-graduação. Assim, quem está na condução de um processo deste tipo deve estar atento aos requisitos específicos de um determinado lugar ou grupo e de cada pessoa envolvida.

Uma outra questão merecedora de destaque é a menção a respeito do momento emocional que o estudante vivencia ao longo do processo. Na elaboração da primeira versão, é comum que se viva um momento de muita incerteza: o autor fica em dúvida, até mesmo, da área temática que gostaria de explorar. O que propomos é que seja feita uma escolha de um tema de interesse entre aqueles expressos pelo estudante e que seja suficientemente desenvolvido a ponto de compor uma primeira versão. Em outras palavras, sair da hesitação ou do temor pela mobilidade; iniciar o processo, dando forma material às primeiras idéias, que serão re-elaboradas, refeitas no próprio caminhar; procurar liberar-se de censuras internas, lançar-se, porque que o momento é de começar.

No intervalo entre as versões, à medida que explora a literatura e participa de alguma discussão, conversação ou troca sobre o problema que está sendo formulado, é freqüente o estudante experimentar sensações de insegurança, inquietude, ansiedade ou angústia e sentir-se fragmentado ou em desconexão com um contexto estruturado. Em outras palavras, instaura-se um processo de desequilíbrio, uma vez que a pessoa está vivenciando a criação de algo novo, desconhecido, incerto. Aqui sugerimos que, após um período de imersão, de contato intenso com as idéias e a sua formulação escrita, o estudante busque vivenciar outros espaços e cenários, mais amplos, abertos; procure outros interlocutores e campos temáticos, conversa, diversão e arte; busque alguma atividade corporal prazerosa e, também, outras condutas que o levem a entrar em contato consigo mesmo e proporcionem, de algum modo, uma harmonia interior. Assim, é possível conseguir um re-equilíbrio de suas estruturas emocionais, cognitivas, cuja recomposição o permitirá encontrar o sentido para 
aquilo que está sendo formulado. Claro que, nesse processo, o objeto de estudo que está sendo composto poderá distanciar-se muito das primeiras idéias, o que é bastante natural e previsível, pois, se, por um lado, as idas e vindas permitem nossa reorganização interior, por outro, dão-nos maior clareza e consistência na forma de expressão escrita do projeto. A vida, o cotidiano são um fluxo contínuo de impressões que não se repetem (Alves, 2000). Assim, também nesses momentos específicos de criatividade, de intensa emoção e cognição, não poderia ser diferente, ou, como disse Heráclito (apud Alves, 2000, p.44): "tudo flui, nada permanece. Não se pode entrar duas vezes num mesmo rio".

\section{Diante do branco: o papel, a tela, o desafio}

A respeito dos novos rumos da ciência, o que vem sendo discutido é o re-encantamento do mundo, no qual o universo narrativo é essencial para a conexão dos saberes. Para Prigogine (2001, p.100)

A ciência é um diálogo, não um solilóquio, como mostram as transformações conceituais às quais fomos levados nas últimas décadas. Na verdade, a ciência faz parte da procura transcendental que é comum a outras tantas atividades culturais: arte, música, literatura.

Sendo a poesia considerada a quintessência da linguagem e, simultaneamente, algo o mais próximo possível da origem, esse movimento é uma tentativa de ser coerente quanto à forma e, em linguagem poética, dizer a gênese do texto a partir de uma palavra. Mas, também, é uma sugestão de como preparar o corpo e o clima propícios à criação. O processo criativo é um diálogo permanente entre o caos e o cosmos: um fluxo entre o abismo, o indiferenciado, o sem-forma, o que ainda não se junta e o borbulhar das palavras, das idéias, dos conceitos, das perguntas. Primeiro, é preciso expandir, andar, ouvir, respirar, para, depois, contrair, concentrar, sentar, respirar. Aqui recordamos Nietzsche (1844-1900), que recomendava só confiar em pensamentos que do movimento vêm vindo... Por isso, não é suficiente apenas o intelecto. Um texto com o corpo todo se escreve; a carne se faz verbo; a luz vira pele.

Sobre a origem do mundo, algumas culturas fazem uma relação de similitude simbólica desse início, unindo a água, o ovo, o caos, o sopro e o verbo (Chevalier \& Gheerbrant, 1988). É nesse espírito que estamos propondo a embriogênese, como uma metáfora do processo criativo do texto, do projeto.

Em meio ao caos, buscar as fontes e os meios de comunicação, de informação, as referências bibliográficas e as pessoas que queiram trocar o saber, compartilhar. Advertimos que, para algumas pessoas, talvez seja importante nesta fase registrar, em um diário, palavras-chave, intuições, imagens, sonhos, livros, filmes, poemas, músicas, consultas à Internet, fantasias, delírios, conversas, idéias e conceitos. Cada etapa é essencial para a construção, pois é um todo o processo criativo.

O momento de escrever o texto é o instante de mergulhar, ainda mais profundamente, no caos, pois é sabido que, dessa massa informe, cria-se uma organização, tal e qual os gases na compressão, formação, fornalha das estrelas. Aqui, tudo o que foi sentido, lido, visto, pesquisado, conversado, vivido e em seu diário registrado - palavras, idéias e conceitos sintéticos - precisa ser relacionado, interconectado, buscando-se correspondências, analogias, divergências, convergências, descartes. Cadência, dança das imagens, ímãs, frases, elos, modelos, montagens. A palavra é quem convoca. No início, é o ritmo: toque, batuque, atabaque, coração sístole-diástole, tesão, onda, flutuação, vibração, respiração. Um texto bem respirado pode ser mais corajoso. Uma simples palavra que fica ressoando pode estimular todo um imaginário. A palavra-chave, a palavra-valise, que contém em si outras

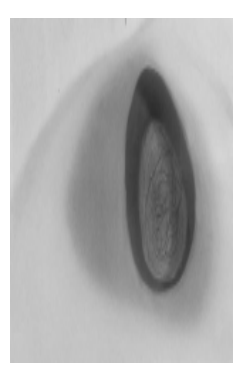


palavras, pode conduzir ao texto: um tecido, uma tessitura, uma tecelagem, um vaivém narrativo, um labirinto, uma tentativa-erro-acerto, risco, jogo, antes de tudo, prazeroso. Nesta fase, os dicionários, especialmente os etimológicos e simbólicos, são ainda mais essenciais, por permitirem distinções, esclarecimentos, classificações, ampliações. É preciso estar aberto ao acaso, ao inesperado, ao improviso, aos acontecimentos fortuitos, misteriosos, sutis, encantados, poéticos, ao que não estava no início, integrando-os ao texto e mesmo transmutando-o.

A pressa é inimiga da afeição. Qualquer gênero de texto precisa de emoção, dedicação, tempo, envolvimento, paixão. Não ter pressa, mas, também, não perder tempo, o que significa dizer: evitar a ansiedade, essa maneira de não estar à vontade em lugar algum, porém sempre em trânsito permanente, inquieto, impaciente. Algo atemporal, o brincar é inerente aos humanos e a outras espécies - é uma arte usufruir o durante. Não rentabilizar cada instante, tempo não é dinheiro; nem se render ao contágio coletivo, que confunde eficiência com velocidade. Temos cronogramas e prazos, mas é preciso saber saborear. Senso do dever, sim, mas nunca esquecer que flui mais fácil o que vem do prazer... Compreendemos o espaço-tempo como uma tentativa do bem-viver. Aprender a ser, para bem dizer. À nossa criatividade se oferece cada dia a ser vivido: é uma música, uma dança, uma pintura, um amor, um poema, uma obra de arte.

\section{A obra aberta vida}

Para a redação do texto, gostaríamos, ainda, de sugerir um roteiro de critérios que pudesse servir de orientação, avaliação, instrumento de navegação. É inspirado no livro Seis propostas para o próximo milênio (Calvino, 1990) e aqui está adaptado livremente. Leveza: linguagem arejada, sóbria, despojada, sem excesso de rebuscamento estilístico nem artificialismo; simples, sutil, delicada, cuidadosa, atraente. Rapidez: é a vibração, o entusiasmo do texto; mesmo que envolva divagações, que salte de um assunto para outro, não perder o fio do relato; evitar redundância, que é comum e necessária na comunicação oral, mas cansativa na escrita. Rapidez de estilo e de pensamento quer dizer agilidade, mobilidade, desenvoltura. Exatidão: senso de medida, parcimônia, precisão; projeto bem definido e calculado; escrita enxuta, sintética - ter coragem de cortar o supérfluo, o excessivo, o que nada acrescenta; uma compressão máxima, exatidão, é a busca do quase inefável, o limite entre o silêncio e a linguagem. Visibilidade: é o jogo entre a visualização e a verbalização do pensamento. A imaginação, embora siga outros caminhos que não os do conhecimento científico, pode coexistir com este último e mesmo ampliá-lo, porque a ciência não precisa ser seca, sem graça. O texto deve evidenciar, de modo claro e raro, as essências e medulas do sentir, pensar, ver, imaginar, ser, fazer. Visibilidade é criar encantamento, imagens memoráveis. Multiplicidade: é abrangência, rede de relações, conexões entre pessoas, fatos, coisas do mundo; analogias, pontes entre os diversos campos dos saberes, dos sabores. É preciso levar em conta a pluralidade, complexidade, especificidade, diversidade e singularidade das linguagens, dos sistemas e estruturas, das culturas. A incompletude é inevitável não só pela imperfeição ou impossibilidade de apreender a coisa em si, mas também pelos limites de expressão inerentes a toda obra. Entretanto esse inacabamento é também necessário para estimular novos desafios e permitir abertura - continuidade, desdobramento e criatividade para nós mesmos e, principalmente, para os outros. Consistência: não houve mais tempo para Calvino (1923-1985). Essa proposta não chegou a ser escrita, porém ousamos imaginá-la. O critério foi etimológico. Em latim con-sistere: ser constituído, compor-se, sustentar-se, fundar-se; perseverança, firmeza, constância, compatibilidade; estar tranqüilo, seguro, senhor de si; ser conduzido a parar, cessar, acabar, terminar (Saraiva, 2000).

Sinuosa, teimosa, autopoiética, incompleta, a vida é obra aberta. E a vida humana, sendo também linguagem, é símbolo, "joga unindo", busca significado. E tudo indica que o que dá 
sentido é a criatividade: inacabada, encantada, infinita... Portanto, nossas criações nunca têm considerações finais. Assim, um texto é sempre aperfeiçoável e um projeto está para ser iniciado; no seu decorrer, é mudado, desdobrado, ampliado. Mas há um momento em que decidimos cessar, terminar, porque, dentre os critérios sugeridos, há consistência. Então, abandonamos a nossa cria, porque ela precisa ganhar o mundo, andar sozinha, por si mesma tentar contribuir e porque, também, o permanente criar traz novas alegrias e a vida continua...

\section{O silêncio}

O tanto que foi escrito sobre a elaboração de textos e projetos é um vasto e precioso acervo. Nossa intenção não é esgotar o assunto, mas agregar algo ao que nos parece serem lacunas desses trabalhos: a insuficiência de indicações quanto à postura corporal, emocional e cognitiva bem como de referências quanto ao próprio processo criativo do texto e do projeto; e ainda pouca ênfase na construção não-linear do processo. Este artigo, e outros desdobramentos das reflexões aqui feitas só foi possível graças à experiência permanente de trocas, dúvidas, tentativas e realizações compartilhadas com os nossos estudantes, aos quais muito agradecemos.

O silêncio do texto é um paradoxo. O texto começa e termina com o silêncio. O silêncio final é um momento de relaxamento, de aconchego, de saborear o dever cumprido e o prazer sentido, de meditar, parar o interior diálogo, silenciar.

\section{Referências}

ALVES, R. Filosofia da ciência: introdução ao jogo e a suas regras. São Paulo: Loyola, 2000.

CALVINO, I. Seis propostas para o próximo milênio. São Paulo: Cia. das Letras, 1990.

BASTOS, L.R.; FERNANDES, L.M.; PAIXÃO, L.; DELUIZ, N. Manual para a elaboração de projetos e relatórios de pesquisa, teses, dissertações e monografias. Rio de Janeiro: Guanabara Koogan, 1995.

BEAUD, M. Arte da tese. Rio de Janeiro: Bertrand Brasil, 1997.

CHEVALIER, J.; GHEERBRANT, A. Dicionário de símbolos. Rio de Janeiro: José Olympio Editora, 1988. CONTANDRIOPOULOS, A. P.; CHAMPAGNE, F.; POTVIN, L.; DENIS, J. L.; BOYLE, P. Saber preparar uma pesquisa: definição, estrutura, financiamento. São Paulo/Rio de Janeiro: Hucitec/Abrasco, 1994.

COSTA, M.A.F.; COSTA, M.F.B. Metodologia da pesquisa: conceitos e técnicas. Rio de Janeiro: Interciência, 2001.

ECO, U. Como se faz uma tese. São Paulo: Perspectiva, 1993.

ENCICLOPÉDIA MIRADOR. São Paulo: Encyclopaedia Britannica do Brasil Ltda, 1986.

FRANÇA, J.L.; VASCONCELLOS A.C.; MAGALHÃES, M.H.A.; BORGES, S.M. Manual para normalização de publicações técnico-científicas. Belo Horizonte: UFMG, 2003.

GARCIA, R. Interdisciplinariedad y Sistemas Complejos. In: LEFF, Enrique. (Org.) Ciencias sociales y formación ambiental. Barcelona: Gedisa,1994. p.41-65.

GARAUDY, R. Dançar a vida. Rio de Janeiro: Nova Fronteira, 1980.

GIL, A.C. Como elaborar projetos de pesquisa. São Paulo: Atlas, 1996.

GOLDENBERG, M. A arte da pesquisa. Rio de Janeiro: Record, 1999.

KANT, I. Crítica da razão pura. São Paulo: Nova Cultural, 1996.

LAKATOS, E.M.; MARCONI, M.A. Metodologia do trabalho científico. São Paulo: Atlas, 1992. 
MATURANA, H R. Emoções e linguagem na educação e na política. Belo Horizonte: UFMG, 2001.

MATURANA, H.R.; VARELA, F.J. A árvore do conhecimento. São Paulo: Palas Athena, 2001.

MATURANA, H.; VERDEN-ZÖLLER, G. Amar e brincar: fundamentos esquecidos do humano. São Paulo: Palas Athena, 2004.

PACHECO, A.C. A dissertação: teoria e prática. São Paulo: Atual Editora, 1988.

PARRA FILHO, D.; SANTOS, J.A. Apresentações de trabalhos científicos: monografia, TCC, teses e dissertações. São Paulo: Futura, 2001.

PERROTTA, C. Um texto pra chamar de seu: preliminares sobre a produção do texto acadêmico. São Paulo: Martins Fontes, 2004.

PIAGET, J. Biologia e conhecimento. Petrópolis: Vozes, 2000.

PRIGOGINE, I. Ciência, razão e paixão. Belém: Eduepa, 2001.

REY, L. Planejar e redigir trabalhos científicos. São Paulo: Edgard Blücher, 1993.

ROTHER, E.T.; BRAGA, M.E.R. Como elaborar sua tese: estrutura e referências. São Paulo: [s.n.], 2001.

RUDIO, F.V. Introdução ao projeto de pesquisa científica. Petrópolis: Vozes, 1999.

SÁ, E.S.; GAUDIE-LEY, M.D.L.M.; FERREIRA, A.L.L.; SOUZA, M. M.; Figueiredo, M. G. G.; SODRÉ, S.M.F.; PITANGA, V. L. B. Manual de normalização de trabalhos técnicos, científicos e culturais.

Petrópolis: Vozes, 1997.

SALOMON, D.V. Como fazer uma monografia. São Paulo: Martins Fontes, 1999.

SARAIVA, F.R.S. Novíssimo dicionário latino-português. Rio de Janeiro: Livraria Garnier, 2000.

SCHRAMM, F. R. Aspectos cognitivos, metodológicos e morais do trabalho dos CEPs. In:CARNEIRO, F. (Org.) A moralidade dos atos científicos: questões emergentes da experiência dos Comitês de Ética em Pesquisa envolvendo seres humanos. Rio de Janeiro: Fiocruz, 1999. p.53-9.

SEVERINO, A.J. Metodologia do trabalho científico. São Paulo: Cortez, 1996.

SPECTOR, N. Manual para a redação de teses, dissertações e projetos de pesquisa. Rio de Janeiro: Guanabara Koogan, 1997.

TOBAR, F.; YALOUR, M.R. Como fazer teses em saúde pública: conselhos e idéias para formular projetos e redigir teses e informes de pesquisas. Rio de Janeiro: Fiocruz, 2001.
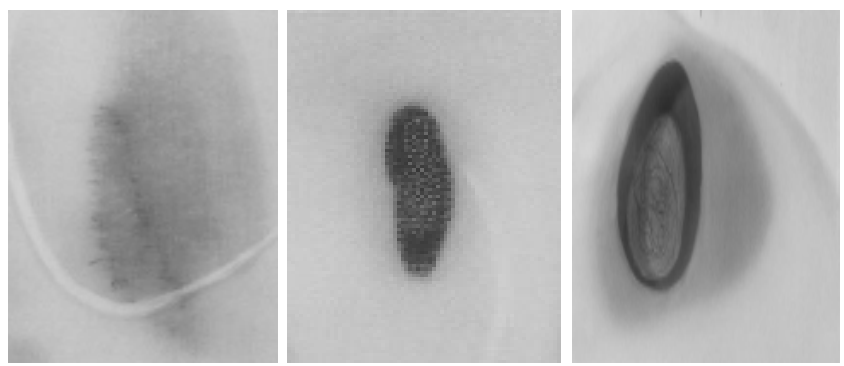
This article aims to contribute to the study of the production of academic texts and research projects by post-graduate students. It relies on the constructivist conception of knowledge, whereby learning is seen as a continuous process of recomposition of cognitive structures, with contributions from Humberto Maturana on the central role of emotion and language in coming-to-be. It is suggested that the metaphor of embryogenesis is an apt one for the evolution of a research project. The research project begins with a template and takes shape during the course of successive phases, like an embryo, attributing its components to undifferentiated cells, which simultaneously differentiate themselves, giving rise to the project as a whole. The article also presents a series of criteria for evaluation of writing and reflection based on flows of emotion and attitudes, as a way of overcoming the challenge posed by the blank page or screen, which can help us to use our creative process in a more productive, consistent and pleasurable manner.

KEYWORDS: creative process; text-production; writing research projects; constructivism; emotion; cognition.

Este artigo pretende contribuir para o processo de criação de textos e projetos de pesquisa acadêmicos por estudantes de pós-graduação. Tomamos por base uma concepção construtivista do conhecimento, a aprendizagem como um processo contínuo de recomposição das estruturas cognitivas e contribuições de Humberto Maturana quanto ao papel central da emoção e da linguagem no nosso devir. É a partir de uma metáfora, a embriogênese, que propomos a geração de um projeto que, partindo de uma estrutura-padrão, vá constituindo-se em movimentos sucessivos, de forma similar ao desenvolvimento embrionário, associando seus componentes a células indiferenciadas que vão, simultaneamente, diferenciando-se e dando origem a esse todo-projeto. Ademais, incorporamos sugestões de um roteiro de critérios, para avaliar a redação, e de reflexões acerca dos fluxos emocionais e atitudes perante o desafio diante do papel ou da tela em branco, que nos podem auxiliar na vivência do processo criativo, de modo mais produtivo, consistente e prazeroso.

PALAVRAS-CHAVE: processo criativo; texto; elaboração de projetos de pesquisa; construtivismo; emoção; cognição.

Este artículo pretende contribuir al proceso de creación de textos y proyectos de investigación académica, por estudiantes de postgrado. Tomamos como base una concepción constructivista del conocimiento; el aprendizaje como un proceso continuo de recomposición de las estructuras cognitivas y contribuciones de Humberto Maturana en lo que respecta al papel central de la emoción y del lenguaje en nuestro devenir. Es a partir de una metáfora, a embriogénesis, que proponemos la generación de un proyecto que, partiendo de una estructura estándar, se va constituyendo en movimientos sucesivos, de forma similar al desarrollo embrionario, asociando sus componentes a células indiferenciadas que van, simultáneamente, diferenciándose y dando origen a ese todoproyecto. Además, incorporamos sugerencias de un guión de criterios, para evaluar la redacción, y de reflexiones acerca de los flujos emocionales y actitudes ante el desafío frente al papel o frente a la pantalla en blanco, que pueden auxiliarnos en la vivencia del proceso creativo, de forma más productiva, consistente y placentera.

PALABRAS CLAVE: proceso creativo; texto; elaboración de proyectos de investigación; constructivismo; emoción; cognición. 